Available online on 15.03.2019 at http://jddtonline.info
Oc 2011-18, publisher and licensee JDDT, This is an Open Access article which permits unrestricted
non-commercial use, provided the original work is properly cited

Open $\overbrace{\text { Access }}$

Research Article

\title{
Fortification role of Curcumin against renal and testicular toxicity of synthetic food dye brilliant blue in rats
}

\author{
Eman G. Mohamed a, Ibrahim M. Abo-laila a and Marwa A. Masoud*b \\ a PhD, Researcher of Molecular Drug Evaluation Department, National Organization for Drug Control and Research (NODCAR), Giza, Egypt. \\ b PhD, Researcher of Pharmacology, Department of Pharmacology, National Organization for Drug Control and Research (NODCAR), Giza, Egypt. \\ P.O. BOX 29
}

\begin{abstract}
Increasing awareness has been lately paid to the toxicity of synthetic additives used in food. The main aim of this study was to survey the renal and testicular toxicity of synthetic food dye brilliant blue. Administration of the brilliant blue (BB) changed body and relative organs weights, serum creatinine, urea (BUN), uric acid and serum FSH, LH, testosterone levels. This study proved that BB induced oxidative damage as manifested by significant increase in Lipid peroxidation with disorganization in the activity of glutathione peroxidase, protein carbonyl and reactive oxygen species content. Histopathological changes include: infiltration and vacuolation in kidney. In addition; degeneration and necrosis of spermatogoneal cells lining seminiferous tubules in testis. Furthermore; BB induced appotosis via activation of casp-3. Administration of curcumin with BB attenuated the cytotoxic effects of brilliant blue on kidney and testis tissues and reducing apoptotic cell death as well as improved the redox status of kidney and testis.
\end{abstract}

Keywords: Brilliant blue dye, Curcumin, Kidney, Testis, Histopathology, Rats.

Article Info: Received 11 Jan 2019; Review Completed 20 Feb 2019; Accepted 20 Feb 2019; Available online 15 March 2019

\section{Cite this article as:}

Mohamed EG, Abo-laila IM, Masoud MA, Fortification role of Curcumin against renal and testicular toxicity of synthetic food dye brilliant blue in rats, Journal of Drug Delivery and Therapeutics. 2019; 9(2):1-8

http://dx.doi.org/10.22270/jddt.v9i2.2448

*Address for Correspondence:

Marwa A. Masoud, PhD, Researcher of Pharmacology, Department of Pharmacology, National Organization for Drug Control and Research (NODCAR), Giza, Egypt. P.O. BOX 29

\section{INTRODUCTION}

A number of food coloring additives are added to improve the appearance of the food items and drinks or any non-food applications including pharmaceuticals $\mathbf{1 , 2}$. Colorant gives an aesthetic semblance to diet ${ }^{3}$. Synthetic organic colorants as Brilliant blue, tartrazine, erythrosine, sunset yellow, fast red E, ponceau 4R, orange GGN, allura red and scarlet GN are widely applied due to their coloring properties, high stability and inexpensive. But; some of them become harmful after prolonged use, causing health problems such as indigestion, anemia and allergic reactions as asthma and urticaria, mental retardation, abnormalities in off-springs, growth retardation and eye defects resulting in blindness $\mathbf{4 , 5}$.

As well, several studies on some synthetic flavors were reported to cause health hazards to consumers. Shousha et al. (1992) 6 found that oral administration of synthetic banana flavors caused energy, carbohydrate, lipid and nucleic acid metabolism disorder in brain, liver and kidney tissues of rats. El-Wahab and El-Deen Moram (2013) ${ }^{7}$ found that ingestion of these food colorants and flavor affected the free radicals system because of its role in tissue damage.

Actually, these colorants are not $100 \%$ safe and its use might prove to be harmful in one way or the other. Food additives are detected one of the xenobiotics that humans are undergoing to exposure $\mathbf{8}$. Its metabolism to large extent takes place in the liver 9 , these metabolites sometimes become more toxic than the initial substance 10. Xenobiotics can produce a serious of biologic effects as pharmacologic responses, toxicity, immunologic response and cancer $\mathbf{8}$.

For years now, it has been established that curcumin is an orange-yellow crystalline powder and has bifunctional natural antioxidant activity in a direct and an indirect way by scavenging free radicals $\mathbf{1 1}$. In addition, there is an extensive study that suggests that curcumin has possibility in the prevention and treatment of a variety of other diseases. Therefore; almost companies are actually providing several curcumin products in the form of drinks, tablets, capsules, 
creams, gels, nasal sprays, extracts and coloring agents for both safe to eat and medical needs $\mathbf{1 2}$.

This study was elucidating the renal and testicular toxic effects of the synthetic dye brilliant blue in rats by determining some of the biochemical parameters, oxidative stress parameters as well as apoptotic factor (Casp-3) and this study demonstrated that curcumin has antioxidant and antiapoptic activity against brilliant blue toxicity.

\section{MATERIALS AND METHODS}

\subsection{Animals:}

Adult male Sprague-Dawley rats weighing 140-150 g were used in the present study. They were obtained from the breeding colony maintained at the animal house of the National Organization for Drug Control and Research (Giza, Egypt). Animals were caged in four groups, given Purina chow, and water was allowed ad libitum. Animals were allowed at least for one week of acclimatization before using them. Animal handling was in accordance to the guidelines of the Research Ethical Committee of the National Organization for Drug Control and Research (NODCAR, Cairo, Egypt) and in accordance to the ethical procedures and policies approved by Ethical Research Committee of Faculty of Pharmacy, Cairo University, Egypt and complied with the Guide for the Care and Use of Laboratory Animals (1996) ${ }^{\mathbf{1 3}}$.

\subsection{Chemicals:}

Food colors additives Brilliant blue was obtained from the local market and administered orally according to (Walton et al., 1999) 14, Curcumin was supplied by Sigma-Aldrich (Germany) in a dose $(50 \mathrm{mg} / \mathrm{kg}$ ) according to Farghaly and Hussein (2010) ${ }^{15}$.

\subsection{Experiment Design:}

Thirty two adult male Sprague-Dawley rats were divided randomly into four groups as follow:

Normal control (NC): Rats were feeding basal diet with one $\mathrm{ml}$ saline solution as a vehicle for 30 days.

Brilliant blue-treated (BB): Rats were fed basal diet and received $20 \mathrm{mg} / \mathrm{kg}$ Brilliant blue orally for 30 days.

Brilliant blue-treated plus curcumin (BB+CUR): Rats were fed basal diet and received curcumin (50 mg/ kg) two hours before the administration of $20 \mathrm{mg} / \mathrm{kg}$ Brilliant blue for 30 days.

Curcumin treatment (CUR): Rats were fed basal diet and received $50 \mathrm{mg} / \mathrm{kg}$ curcumin alone orally for 30 days.

\subsection{Tissue Sampling:}

At the end of the experimental period, all rats were fasted for 12 hours and then the blood samples were collected from venous sinus in centrifuge tubes to separate serum by centrifugation at $3000 \mathrm{rpm}$ for 15 minutes. Sera were kept at $-80^{\circ} \mathrm{C}$ for biochemical analyses. In addition, the kidney and the testis were dissected and isolated immediately, plotted free from adhering blood, and dried between two filter papers. Each tissue sample was then weighed. Parts from kidney and testis were kept in $10 \%$ formalin to examine histologically and the other parts were kept at $-80^{\circ} \mathrm{C}$ for biochemical examination in kidney and testis tissues.

\subsection{Biochemical Examination:}

The kidney and testis tissues were homogenized in sodium phosphate buffer ( $\mathrm{pH}$ 7.2) using a Teflon homogenizer
(Heidolph Silent Crusher M),and then the homogenates were centrifuged at $10,000 \times$ g for 15 min at $4{ }^{\circ} \mathrm{C}$.

\subsubsection{Measurement of blood urea nitrogen (BUN),} creatinine and uric acid:

Colorimetric assay kits for the measurement of BUN (Wybenga et al., 1971) ${ }^{16}$, creatinine (Henry, 1974) ${ }^{17}$ and uric acid (Young, 2001) 18 levels (Diamond Diagnostics, Cairo, Egypt).

2.5.2. Measurement of serum FSH, LH and total Testosterone concentrations:

In the serum were measured using commercial radio-amino assay (RIA) kits (NanJing Jiancheng Co. Lot DF00008).

\subsubsection{Determination of reactive oxygen species (ROS) content:}

ROS was determined in both tissues homogenate according to the method of Vrablic et al. (2001) ${ }^{19}$.

\subsubsection{Determination of lipid peroxidation content (LPO):}

Lipid peroxides formation was determined in both tissues homogenate as thiobarbituric acid reactive substances (TBARS). It was determined according to the method of Uchiyama and Mihara (1978) 20.

\subsubsection{Determination of protein carbonyl content (PC):}

Protein carbonyl concentration was measured in both tissues by first forming labeled protein hydrazone derivatives using 2, 4-dinitrophenyl hydrazide (Smerjac and Bizzozero, 2008) 21.

2.5.6. Measurement of glutathione peroxidase (GPx) Activity:

GPx activity was measured using $\mathrm{H}_{2} \mathrm{O}_{2}$ as substrate according to the method described by Brigelius-Flohe (1999) ${ }^{22}$. The reaction was monitored indirectly as the oxidation rate of NADPH at $240 \mathrm{~nm}$ for $3 \mathrm{~min}$. Enzyme activity was expressed as $\mathrm{nmol} / \mathrm{mg}$ protein.

\subsubsection{Histopathology}

For histopathological examination, kidney and testis tissues were dissected and tissue samples were fixed in $10 \%$ neutral formalin for $24 \mathrm{~h}$. Then samples were processed using a graded ethanol series and embedded in paraffin. Paraffin sections were cut into $6 \mu \mathrm{m}$-thick slices and stained with hematoxylin and eosin (H\&E) for light microscopic examination (Banchroft et al., 1996) ${ }^{23}$.

\subsubsection{Immunohistochemical Staining of Caspase-3(Casp- 3):}

The paraffinic testis and kidney were cut into $5-\mu \mathrm{m}$ sections and launched on positively charged slides for caspase-3 IHC. Sections were dewaxed, rehydrated and autoclaved at $120^{\circ} \mathrm{C}$ for $10 \mathrm{~min}$ in $10 \mathrm{~mm}$ citrate buffer (pH 6). Wash used PBS ( $\mathrm{pH} 7.2$ ) and then added $0.3 \% \mathrm{H}_{2} \mathrm{O}_{2}$ in methanol for $15 \mathrm{~min}$ for blocking endogenous peroxidase. Slides washed again in PBS, and blocking were completed by adding blocking buffer. Incubate for $30 \mathrm{~min}$ at room temperature. Caspase- 3 Polyclonal Antibody (Cat. No. PA1- 29157, Thermo Fisher Scientific Co., USA) was added after dilution by PBS $(1: 1,000)$ and incubated for $30 \mathrm{~min}$. The slides were washed three times with wash buffer each for 3 min. Secondary antibody (Cat. No. 61-9520, Thermo Scientific Co., USA) were applied to tissue sections and incubated for $30 \mathrm{~min}$. The slides were washed three times for 3 min with wash buffer. Metal 
Enhanced DAB Substrate Working solutions were added to the tissue and incubated 10-min wash two times for $3 \mathrm{~min}$ each with wash buffer. An adequate amount of haematoxylin stain was added to the slide to cover the entire tissue surface for counterstaining.

\subsection{Statistical Analysis:}

All values were presented as means \pm standard error of the means (SEM). Statistical analysis was performed using GraphPad Prism version 5 (Graph-Pad, San Diego, CA). A comparison between different groups was carried out using one-way analysis of variance (ANOVA), followed by a TukeyKramer's multiple comparisons test. A difference was considered significant when P less than 0.05.

\section{RESULTS}

3.1. Comparison between injected brilliant blue only and curcumin with brilliant blue on \% change in body weight and relative kidney and testis weights:

As shown in table (1); compared to the normal control group, there was statistically significantly increased in relative testis weight $(16 \%)$ and body weight ( 3 folds) in group received dyes brilliant blue alone. The administration of curcumin with brilliant blue nearly normalized relative testis and body weights against brilliant blue toxicity when compared with the group of rats received brilliant blue alone.

Table 1: Comparison between injected brilliant blue only and curcumin with brilliant on \% change in body weight and relative kidney and testis weights after 30 days of treatment.

\begin{tabular}{|l|c|c|c|}
\hline \multicolumn{1}{|c|}{ Groups } & \% Change in Body weight & $\begin{array}{c}\text { Relative Kidney weight } \\
\text { (\%) }\end{array}$ & $\begin{array}{c}\text { Relative Testis weight } \\
\text { (\%) }\end{array}$ \\
\hline Normal Control & $11.71 \pm 0.24$ & $0.87 \pm 0.06$ & $2.62 \pm 0.10$ \\
\hline BB & $43.71^{*} \pm 0.24$ & $0.86 \pm 0.07$ & $3.05^{*} \pm 0.03$ \\
\hline CUR+BB & $12.89^{\#} \pm 0.16$ & $0.86 \pm 0.04$ & $2.52^{\#} \pm 0.07$ \\
\hline CUR & $11.40^{\#} \pm 0.23$ & $0.87 \pm 0.01$ & $2.65^{\#} \pm 0.06$ \\
\hline
\end{tabular}

Data are expressed as means \pm SEM of six rats per group. $\quad$ *Significantly different from the normal control group.

\#Significantly different from BB group using one-way ANOVA followed by the Tukey-Kramer test for multiple comparisons test at $\mathrm{P} \leq 0.05$.

\subsection{Kidney Function Parameters:}

-As shown in figure (1), at the end of the experiment BB induced a significant increase in BUN (53\%), creatinine $(100 \%)$ and uric acid (32\%) levels as compared with normal control rats. While administration of CUR significantly decreased BUN (31\%), creatinine (57\%) and uric acid (28\%) levels as compared with BB-treated rats.

\subsection{Hormonal Parameters:}

-As shown in figure (2), BB induced a significant decrease in serum FSH (46\%), LH (50\%) and Testosterone (21\%) levels as compared with normal control rats. On the other hands, treatment with CUR significantly increased serum FSH (87\%), LH (78\%) and Testosterone (20\%) levels as compared with BB-treated rats.
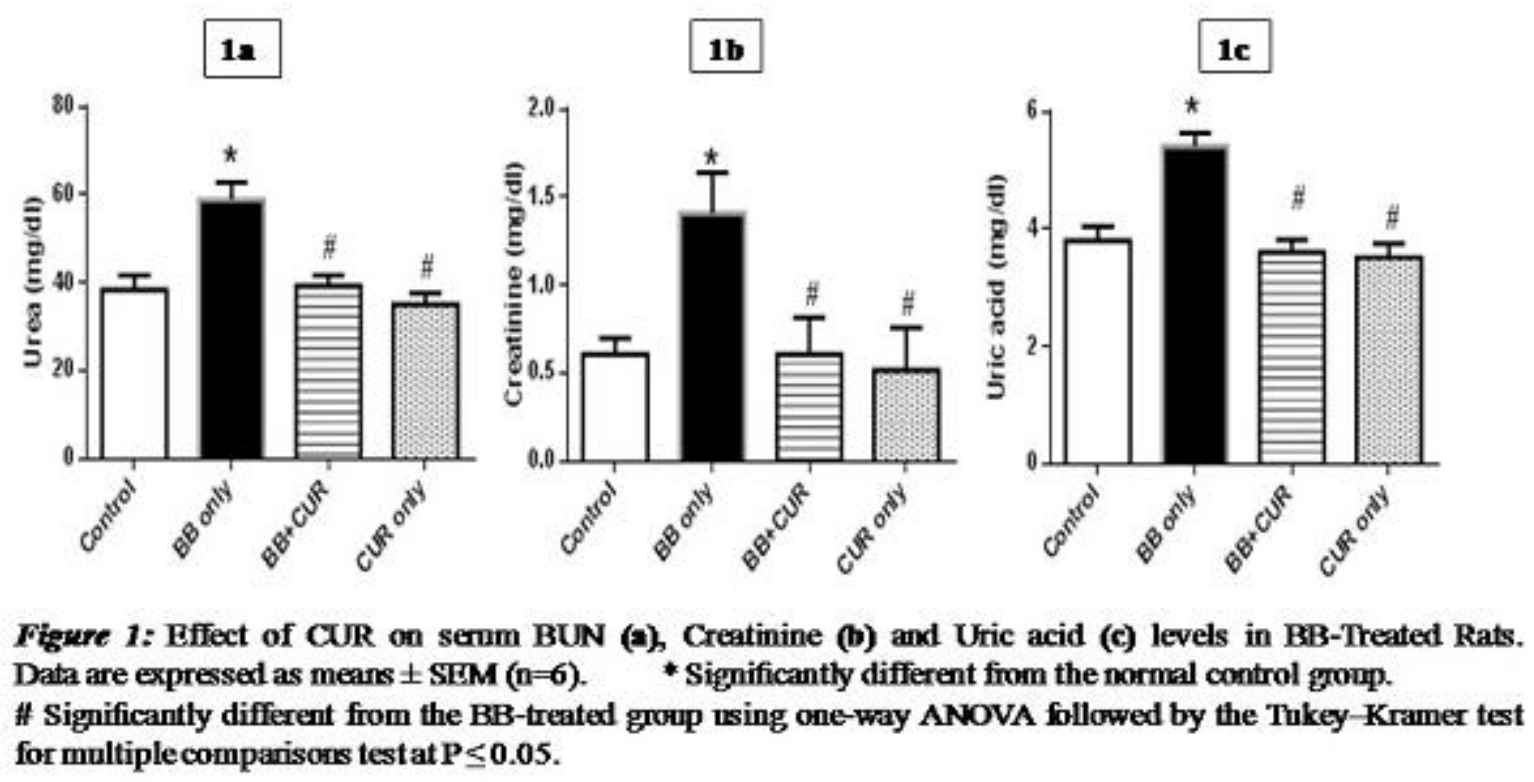

Figure 1: Effect of curcumin (CUR, $50 \mathrm{mg} / \mathrm{kg}$ ) on serum BUN (a), creatinine (b) and uric acid (c) levels in brilliant blue (BB; 20 $\mathrm{mg} / \mathrm{kg}$ ) treated rats.

Data are expressed as means \pm SEM $(n=6) . *$ Significantly different from the normal control group. \# Significantly different from the BB-treated group using one-way ANOVA followed by the Tukey-Kramer test for multiple comparisons test at $\mathrm{P} \leq 0.05$. 

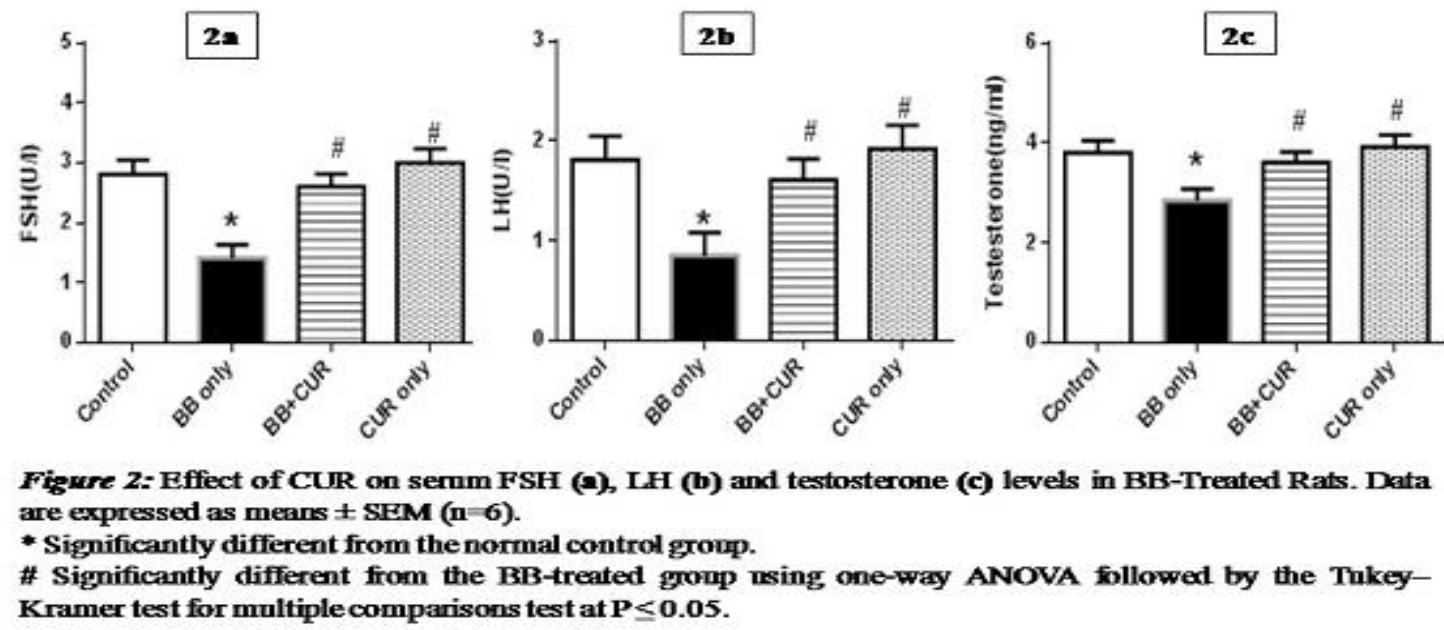

Figure 2: Effect of curcumin (CUR, $50 \mathrm{mg} / \mathrm{kg}$ ) on serum FSH (a), LH (b) and testosterone (c) levels in brilliant blue (BB; 20 $\mathrm{mg} / \mathrm{kg}$ ) treated rats.

Data are expressed as means \pm SEM $(n=6) . *$ Significantly different from the normal control group. \# Significantly different from the BB-treated group using one-way ANOVA followed by the Tukey-Kramer test for multiple comparisons test at $\mathrm{P} \leq 0.05$.

\subsection{Oxidative Stress Parameters in Kidney and Testis Homogenate:}

-As shown in table (2), BB induced a significant decrease in kidney GPx (17\%) accompanied with significant increase in kidney ROS (25\%), PC (42\%) and LPO (3 folds) contents as compared with normal control rats. On the other hands; treatment with CUR significantly increased in kidney GPx $(18 \%)$ accompanied with significant decrease in kidney ROS (18\%), PC (28\%) and LPO (74\%) contents as compared with BB-treated rats.

Table 2: Comparison between oral administration of brilliant blue only and curcumin with brilliant blue on kidney GPx, ROS, PC and LPO contents after 30 days of treatment.

\begin{tabular}{|c|c|c|c|c|}
\hline \multirow[b]{2}{*}{ Groups } & \multicolumn{4}{|c|}{ Oxidative stress in kidney } \\
\hline & $\begin{array}{c}\text { GPx } \\
\text { (IU/g protein) }\end{array}$ & $\begin{array}{c}\text { ROS } \\
(\mu \mathrm{mol} \text { NBT } / \mathrm{g} \text { tissue })\end{array}$ & $\begin{array}{c}\mathrm{PC} \\
\text { (nmol / mg) }\end{array}$ & $\begin{array}{c}\text { LPO } \\
\text { (nmol/ mg protein) }\end{array}$ \\
\hline Normal control & $23.19 \pm 0.63$ & $16.44 \pm 0.29$ & $28.00 \pm 0.62$ & $0.32 \pm 0.83$ \\
\hline BB & $19.28 * \pm 0.19$ & $20.62 * \pm 0.63$ & $39.70 * \pm 0.51$ & $1.30 * \pm 0.15$ \\
\hline CUR+BB & $22.71^{\#} \pm 0.62$ & $17.00^{\#} \pm 0.52$ & $28.60^{\#} \pm 0.44$ & $0.34^{\#} \pm 0.44$ \\
\hline CUR & $23.17^{\#} \pm 0.28$ & $16.46^{\#} \pm 0.43$ & $27.80^{\#} \pm 0.69$ & $0.30^{\#} \pm 0.21$ \\
\hline
\end{tabular}

Data are expressed as means \pm SEM $(n=6) . *$ Significantly different from the normal control group. \#Significantly different from the BB-treated group using one-way ANOVA followed by the Tukey-Kramer test for multiple comparisons test at $\mathrm{P} \leq 0.05$.

As shown in table (3), BB induced a significant decrease in testis GPx (32\%) accompanied with significant increase in testis ROS (53\%), PC (40\%) and LPO (3 folds) contents as compared with normal control rats. On the other hands; treatment with CUR significantly increased in testis GPX (44\%) accompanied with significant decrease in testis ROS (34\%), PC (20\%) and LPO (73\%) contents as compared with BB-treated rats.

Table 3: Comparison between oral administration of brilliant blue only and curcumin with brilliant blue on kidney GPx, ROS, PC and LPO contents after 30 days of treatment.

\begin{tabular}{|l|c|c|c|c|}
\hline \multirow{2}{*}{ Groups } & \multicolumn{4}{|c|}{ Oxidative stress in testis } \\
\cline { 2 - 5 } & $\begin{array}{c}\text { GPX } \\
\text { (IU/ mg protein) }\end{array}$ & $\begin{array}{c}\text { ROS } \\
\text { ( } \boldsymbol{m} \text { mol NBT/g tissue) }\end{array}$ & $\begin{array}{c}\text { PC } \\
\text { (nmol / mg) }\end{array}$ & $\begin{array}{c}\text { LPO } \\
\text { (nmol/ mg protein) }\end{array}$ \\
\hline Normal control & $15.43 \pm 0.28$ & $6.18 \pm 0.51$ & $16.14 \pm 0.19$ & $0.40 \pm 0.51$ \\
\hline BB & $10.42^{*} \pm 0.54$ & $9.44^{*} \pm 0.32$ & $22.62^{*} \pm 0.51$ & $1.52^{*} \pm 0.38$ \\
\hline CUR+BB & $15.00^{\#} \pm 0.71$ & $6.21^{\#} \pm 0.44$ & $18.03^{\#} \pm 0.62$ & $0.41^{\#} \pm 0.27$ \\
\hline CUR & $15.91^{\#} \pm 032$ & $6.03^{\#} \pm 0.62$ & $15.46^{\#} \pm 0.51$ & $0.38^{\#} \pm 0.25$ \\
\hline
\end{tabular}

Data are expressed as means \pm SEM $(n=6)$.*Significantly different from the normal control group. \#Significantly different from the BB-treated group using one-way ANOVA followed by the Tukey-Kramer test for multiple comparisons test at $\mathrm{P} \leq 0.05$.

3.5. Effect of CUR on histopathological alterations and Casp-3 immunoreactivity in BB-induced toxicity in rats:

-Hematoxylin \& eosin (H\&E, 400x) stained kidney sections demonstrated in Figure (3); photomicrograph representing ISSN: 2250-1177 kidney of normal control rat showed normal histological structure of renal parenchyma. Administration of BB showed vacuolation of epithelial lining renal tubules, congestion and vacuolation of glomerular tuft. Daily administration of 
CUR+BB showing congestion of glomerular tuft and intertubular renal blood vessels is still observed. On the other hands, administration of CUR only showed no histopathological changes.

-Hematoxylin \& eosin (H\&E, 400x) stained testis sections demonstrated in Figure (4); photomicrograph representing testis of normal control rat showed normal histological structure of seminiferous tubule with normal spermatogoneal cells and complete spermatogenesis. Administration of BB showed small diameter seminiferous tubules associated with degeneration and necrosis of spermatogoneal cells lining seminiferous tubules. Daily administration of CUR+BB showed no histopathological changes and complete spermatogenesis with sperm production. Similarly, administration of CUR only showed no histopathological changes and complete spermatogenesis with sperm production.
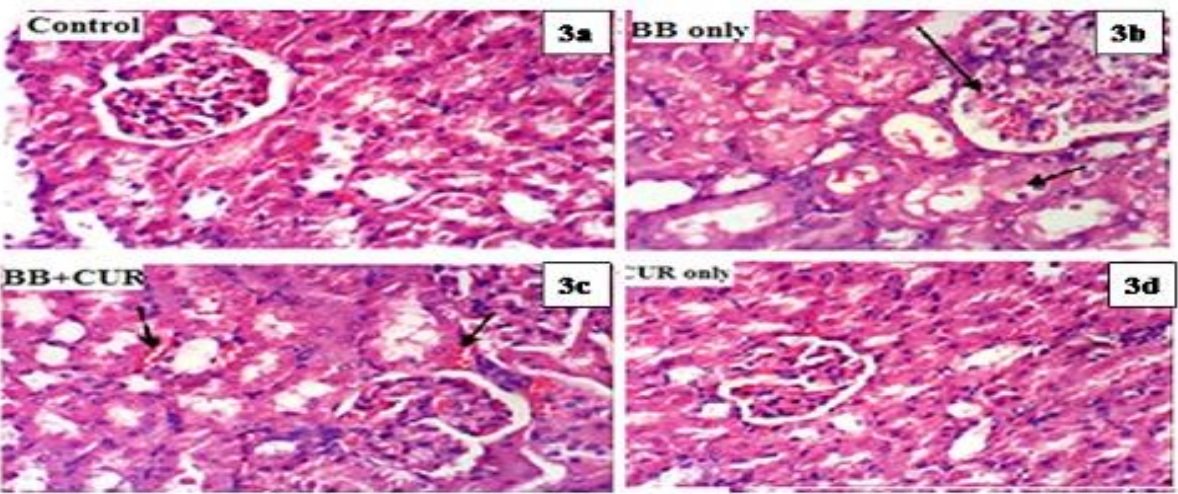

Fiavre 3: Hematoxylin \& eosin (H\&E, 400x) stained kidney sections. normal control rat showed nomsal histological structure of renal parenchyma (a). Administration of BB showed vacbolation of epithelial lining renal tubnles, congestion and vacnolation of glomernlar tnft (b). Daily administration of CUR+BB showing congestion of glomerniar tnft and intertnbubar renal blood vessels is still observed (c). On the other hands, administration of CUR only showed no histopathological changes (d).

Figure 3: Hematoxylin \& eosin (H\&E, 400x) stained kidney sections. Normal control rat showed normal histological structure of renal parenchyma (a). Administration of BB showed vacuolation of epithelial lining renal tubules, congestion and vacuolation of glomerular tuft (b). Daily administration of CUR+BB showing congestion of glomerular tuft and intertubular renal blood vessels is still observed (c). On the other hands, administration of CUR only showed no histopathological changes (d).

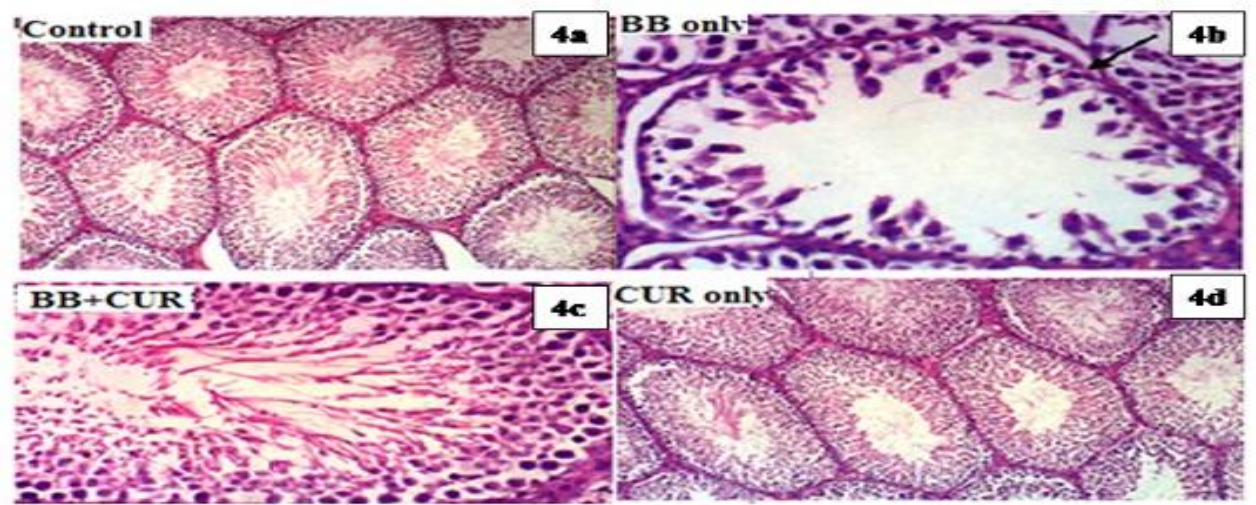

\begin{abstract}
Figrere 4: Hematoxylim \& eosin (H\&E, 400x) stamed testis sections. normal control rat showed normal histological strnctnre of seminiferons tubnle with normal spermatogoneal cells and complete spermatogenesis (a). Administration of BB showed small diameter seminiferous tubules associated with degeneration and necrosis of spermatogoneal cells lining seminiferons tubules (b). Daily administration of CUR +BB showed no histopathological changes and complete spermatogenesis with sperm prodnction (c). Similarly, administration of CUR only showed no histopathological changes and completes permatogenesis with sperm production (d).
\end{abstract}

Figure 4: Hematoxylin \& eosin (H\&E, 400x) stained testis sections. Normal control rat showed normal histological structure of seminiferous tubule with normal spermatogoneal cells and complete spermatogenesis (a). Administration of BB showed small diameter seminiferous tubules associated with degeneration and necrosis of spermatogoneal cells lining seminiferous tubules (b). Daily administration of CUR+BB showed no histopathological changes and complete spermatogenesis with sperm production (c). Similarly, administration of CUR only showed no histopathological changes and complete spermatogenesis with sperm production $(\mathrm{d})$. 

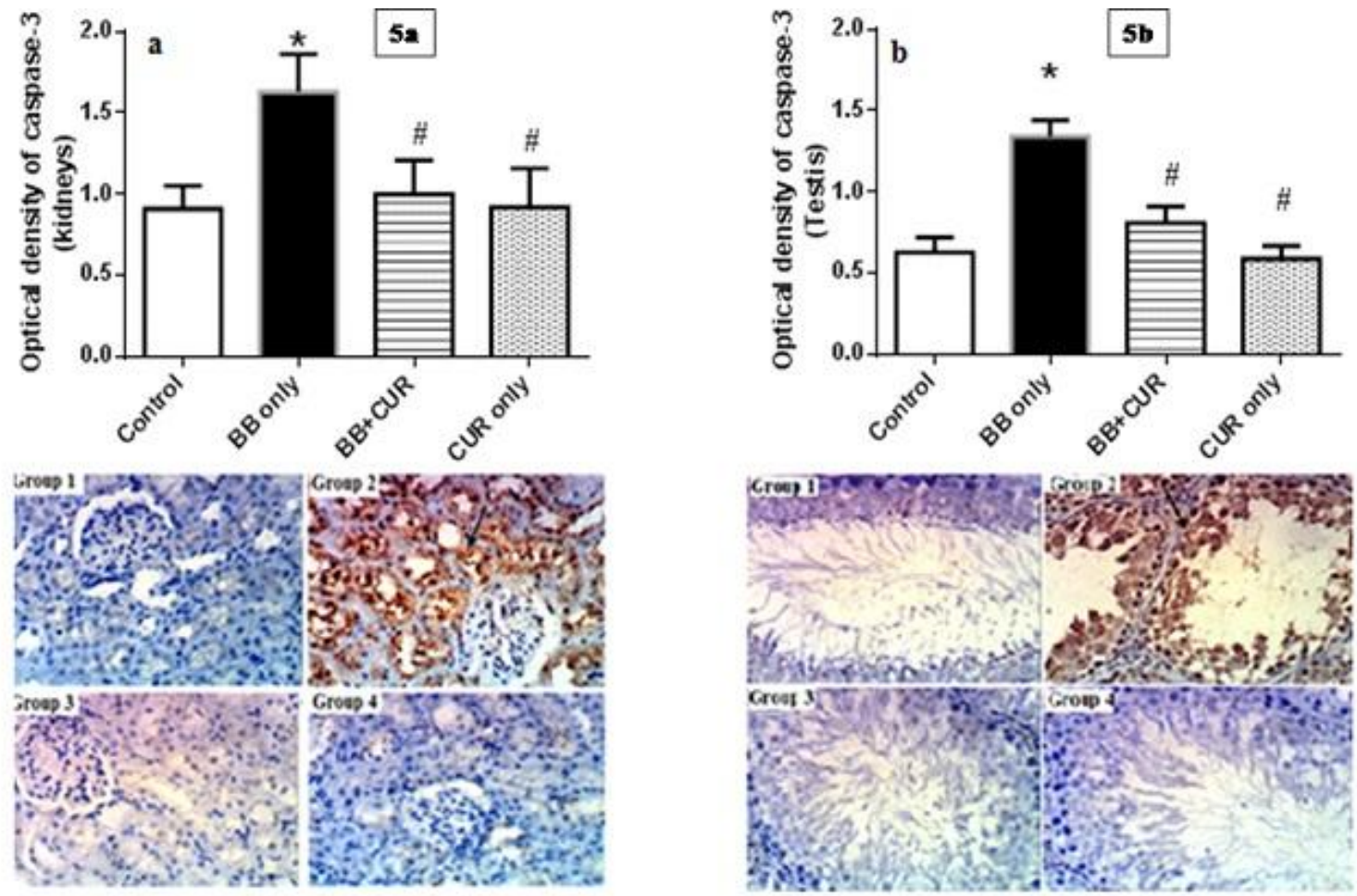

Figure 5: Ameliorative effects of CUR (50 $\mathrm{mg}$ ) on optical density of caspase-3 expression in kidney (a) and testis (b) tissues in BB blue (20 mg/kg) induced kidney-testis injuries in male rats.

Figure 5: Ameliorative effects of curcumin (CUR, $50 \mathrm{mg} / \mathrm{kg}$ ) on optical density of caspase-3 expression in kidney (a) and testis (b) tissues in brilliant blue (BB; $20 \mathrm{mg} / \mathrm{kg}$ ) induced kidney-testis injuries in male rats.

\section{DISCUSSION}

In the present study, the brilliant blue treatment augmented the weight of testes as well as body weight compared to control group this results are similar to Chatterjea and Shinde (2002) ${ }^{24}$ they found that, there is the toxic effect of a dye could be analyzed by monitoring alterations in the body weight of the animals. Meanwhile the administration of curcumin with brilliant blue showed that, the curcumine nullifies the toxic effect of brilliant when compare to group given brilliant blue alone. This finding is in similar with the reported of Mishra and Palanivelu, 2008; Nair et al. (2010) ${ }^{25,} 26$ who reported that, Curcumin is classified as a polyphenol compound that gives turmeric its bright yellow color. Besides being a communal dietary complement, it is used as a food coloring tool. Curcumin holds a high place in ayurvedic medicine as a "cleanser of the body" and today, science has documented several diseased conditions that can be healed by the vital components of turmeric.

In an animal study, the effects of brilliant blue on serum urea, creatinine and uric acid showed that increased level compared to control groups. This is in agreement with Helal et al. (2000) 27 who found a significant elevation in serum creatinine and urea in rats that consumed a synthetic or natural food colorants afte r 30 days of treatment. Moreover, the present results are ina ccordance with data reported by Ashour and Abdelaziz (20 09) ${ }^{28}$ who observed a significant elevation in serum creatini ne and urea levels of rats dosed with organic azo dye (fast green) orally for 35 days. On the other hands; groups treated curcumin with brilliant blue, showed protect the kidneys against the toxicity of brilliant dye comparing to the group of rats treated with brilliant blue alone. The results agreement by Yousef et al. (2008) ${ }^{29}$ who reported that curcumin significantly improved creatinine and urea clearance, another report by Jagadeesh et al. (2009) 30 ISSN: 2250-1177 showed that hepatic-carcinogen exposed rats treated with curcumin showed an amelioration of the altered biochemical parameters (urea, creatinine) giving an indication of the protective effects of curcumin on hepatocarcinogenesis induced in rats.

The brilliant blue-treated rats showed increased level of Lipid peroxidation index (LPO), protein carbonyl (PC), and reactive oxygen species (ROS) and decreased level of glutathione peroxidase (GPx) in homogenate kidney and testes as compared to control. These findings clearly proved the oxidative toxic effect of brilliant blue on kidneys and testes tissue through the generation of free radicals and disorganization of the redox statues. This finding is in agreement with the results of Himri et al. (2011) ${ }^{31}$, a study has demonstrated the generation of ROS by food colours which could induce oxidative stress. Production of ROS in an organism was correlated to the decreased levels of antioxidant enzymes, which results in oxidative stress ${ }^{32}$. The oxidative stress is due to the disruption of the equilibrium between production of free radicals and their being scavenged by the antioxidant system ${ }^{33}$. As a result of ROS formation, the antioxidant defense mechanism of the cells including SOD, CAT and GSH began to prevent the cell death by these toxic radicals so their levels in the tissue homogenate were decreased specially at higher doses 34 .

In the present study, observed the effect of brilliant blue (BB) administration $(20 \mathrm{mg} / \mathrm{kg}$ ) caused a significant reduce in serum luteinizing hormone (LH), follicle stimulating hormone (FSH), testosterone accompanied with significant increase kidney function parameters; these findings are in accordance with Mahmoud (2006) ${ }^{35}$ who found that the most significant adverse effects of the brilliant blue dye on the testis tissue is probably a direct inhibition of testosterone levels. Meanwhile the obtained results revealed the administration of curcumin with brilliant blue showed ameliorative effect in serum luteinizing hormone (LH), 
follicle stimulating hormone (FSH) and testosterone level when compared to the group rats received brilliant blue alone. This finding reflects the powerful of curcumin on remove brilliant toxicity through cellular metabolic processes. The principal colouring components of curcumin scavenge free radicals at the cost of becoming weak free radicals themselves $\mathbf{1 5}$.

The antioxidants are another subgroup of the preservatives, essential to extend the shelf life of many food stuffs. Antioxidants as curcumin prevent the oxidation of molecules by donating a hydrogen atom or an electron, becoming themselves reduced, in the radical form, but contrary to other radicals, antioxidants when in radical form are stable and do not allow further reactions to take place 36. Food antioxidants are used for extending shelf life and impeding decay while not adding taste or odors to food or modify appearance ${ }^{37}$.

\section{CONCLUSION}

The addition of synthetic color, specifically at high concentration and for a long time leads to harmful biochemical and histological effects on body organs. Meanwhile, curcumin has been recognized as an important therapeutic natural product with high medical value as a strong natural antioxidant. Despite the large number of papers, a very small number of clinical trials were conducted specifically on humans in order to fully confirm and prove its effectiveness and more attention should be paid towards using curcumin as natural colorants.

\section{ACKNOWLEDGMENT}

The authors would like to thank Prof. Dr. Kawkab A. Ahmed (Pathology Department, Faculty of Veterinary Medicine, Cairo University, Egypt) for their assistance in the histopathological examinations.

\section{CONFLICT OF INTEREST}

The authors declare no conflict of interest.

\section{REFERENCES}

1- de Boer L. Biotechnological production of colorants. Adv. Biochem. Eng.Biotechnol; 2014; 143:51e89.

2- Newsome AG, Culver CA and van Breemen, RB. Nature's palette: the search for natural blue colorants. J Agric Food Chem; 2014; 62:6498e6511.

3- Dixit S, Purshottam SK, Khanna SK and Das M. Usage pattern of synthetic food colours in different states of India and exposure assessment through commodities preferentially consumed by children. Food Addit Contam Part A Chem Anal Control Expo Risk Assess; 2011; 28:996-1005.

4- Ashida H, Hashimoto T, Tsuji S, Kanazawa K and Danno G, Synergistic effects of food colors on the toxicity of 3-amino-1,4dimethyl-5H pyrido-indole in primary cultured rat hepatocytes. Journal of Nutritional Science and Vitaminology; 2000; 46(3):130-136.

5- Moutinho ILD, Bertges LC and Assis RVC, Prolonged use of the food dye tartrazine and its effects on the gastric mucosa of Wistar rats. Brazilian Journal of Biology; 2007; 67(1):141-145.

6- Shousha MA, Sakr AA, Hammam MA and Abdel-Moein NM. Effect of synthetic banana food additives on energy and nucleic acids metabolism in brain, liver and kidney tissues of albino rats. Egyptian Journal of Applied Sciences; 1992; 7(7):45-55.

7- El-Wahab HM and El-Deen Moram GS. Toxic effects of some synthetic food colorants and/or flavor additives on male rats. Toxicology and industrial health; 2013; 29(2):224-32.

8- Iovdijová A and Bencko V (2010). Potential risk of exposure to selected xenobiotic residues and their fate in the food chain-Part. I: Classification of xenobiotics. Annals of Agricultural and Environmental Medicine; 17(2):183-92.
9- Vrzal R, Ulrichová J and Dvorak Z. Aromatic hydrocarbon receptor status in the metabolism of xenobiotics under normal and pathophysiological conditions. Biomed Pap Med Fac Univ Palacky Olomouc Czech Repub; 2004; 148(1):3-10.

10- Onyema 00, Farombi EO, Emerole GO, Ukoha AI and Onyeze GO. Effect of vitamin $\mathrm{E}$ on monosodium glutamate induced hepatotoxicity and oxidative stress in rats. Indian Journal of Biochemistry \& Biophysics; 2006; 43:20-24.

11- Trujillo J, Chirino YI, Molina-Jijón E, Andérica-Romero AC, Tapia $\mathrm{E}$ and Pedraza-Chaverrí J. Renoprotective effect of the antioxidant curcumin: Recent findings. Redox Biol; 2013; $1(1): 448-56$.

12- Koeberle A and Werz O. Multi-target approach for natural products in inflammation. Drug Discov Today; 2014; 19:18711882.

13- Institute of Laboratory Animal Resources. Guide for the care and use of laboratory animals, 8th edition. Washington, DC: National Academy Press; 1996.

14- Walton K, Walker R, Van De Sandt JJM and Castell JV. The Application of In Vitro in the Derivation of the Acceptable Daily Intake of Food Additives. Food Chem Toxicol; 1999; 37:1175-1197.

15- Farghaly HS and Hussein MA. Protective effect of curcumin against paracetamol-induced liver damage. Australian Journal of Basic and Applied Sciences; 2010; 4(9):4266-4274.

16- Wybenga DR, Glorgio JD and Pileggi VJ. Manual and automated methods for urea nitrogen measurement in whole serum. Clin Chem; 1971; 17:891-895.

17- Henry RJ (1974). Determination of serum creatinine. Clinical Chemistry: Principles and Techniques. 2nd ed. Harper and Row Publishers, New York.

18- Young DS (2001). Effects of disease on clinical lab. testes. 4th ed., AACC.

19- Vrablic AS, Albright CD, Craciunescu CN, Salganik RI and Zeisel SH. Altered mitochondrial function and overgeneration of reactive oxygen species precede the induction of apoptosis by 1 0-octadecyl-2-methyl-rac-glycero-3-phosphocholine in p53defective hepatocytes. The FASEB Journal; 2001; 15(10):17391744.

20- Uchiyama M and Mihara M. Determination of malonaldehyde precursor in tissue by thiobarbituric acid test. Anal Biochem; $1978 ;(86): 271-278$.

21-Smerjac SM and Bizzozero OA. Cytoskeletal protein carbonylation and degradation in experimental autoimmune encephalomyelitis. Journal of neurochemistry; 2008; 105(3):763-772.

22- Brigelius-Flohe R. Tissue-specific functions of individual glutathione peroxidases. Free Radic Biol Med; 1999; 27:951965.

23- Banchroft JD, Stevens A and Turner DR. Theory and practice of histological techniques, 4th edition. New York: Churchill Livingstone. 1996.

24- Chatterjea MN and Shinde R (2002). Text Book of Medical Biochemistry, fifth ed. Jaypee Brothers, Medical Publishers Ltd., New Delhi, p. 317.

25- Mishra S and Palanivelu K. The effect of curcumin (turmeric) on Alzheimer's disease: An overview. Ann Indian Acad Neurol; 2008; 11:13-19.

26- Nair HB Sung B, Yadav VR, Kannappan R, Chaturvedi MM and Aggarwal BB. Delivery of antiinflammatory nutraceuticals by nanoparticles for the prevention and treatment of cancer. Biochem Pharmacol; 2010; 80:1833-1843.

27- Helal EG, Zaahkouk SA and Mekkawy HA. Effect of some food colorants (synthetic and natural products) of young albino rats. I-Liver and kidney functions. The Egyptian Journal of Hospital Medicine; 2000; 1:103-113.

28- Ashour AA and Abdelaziz I. Role of fast green on the blood of rats and the therapeutic action of vitamins C or E. Int J Integr Biol; 2009; 6(1):6-11.

29- Yousef MI, El-Demerdash FM and Radwan FM. Sodium arsenite induced biochemical perturbations in rats: ameliorating effect of curcumin. Food and Chemical Toxicology; 2008; 46(11):35063511.

30- Jagadeesh MC, Sreepriya M, Bali G and Manjulakumari D. Biochemical studies on the effect of curcumin and embelin during N-nitrosodiethylamine/phenobarbital induced- 
hepatocarcinogenesis in wistar rats. African Journal of Biotechnology; 2009; 8(18).

31- Himri I, Bellahcen S, Souna F, Belmekki F, Aziz M, Bnouham M, Zoheir J, Berkia Z, Mekhfi H and Saalaoui E. A 90-day oral toxicity study of tartrazine, a synthetic food dye, in wistar rats. Group; 2011; 300:00

32- El-Tohamy MM. The mechanisms by which oxidative stress and free radical damage produces male infertility. Life Sci J; 2012; 9(1):674-688.

33- Kaneto H, Katakami N, Matsuhisa M and Matsuoka TA. Role of reactive oxygen species in the progression of type 2 diabetes and atherosclerosis. Mediators of inflammation. 2010.

34- Amin KA, Hameid II HA and Elsttar AA. Effect of food azo dyes tartrazine and carmoisine on biochemical parameters related to renal, hepatic function and oxidative stress biomarkers in young male rats. Food and Chemical Toxicology; 2010; 48(10):29942999.

35- Mahmoud NH. Toxic effects of the synthetic food dye brilliant blue on liver, kidney and testes functions in rats. J Egypt Soc Toxicol; 2006; 34:77-84.

36- Carocho $M$ and Ferreira IC. A review on antioxidants, prooxidants and related controversy: natural and synthetic compounds, screening and analysis methodologies and future perspectives. Food and chemical toxicology; 2013; 51:15-25.

37- Nanditha BR, Jena BS and Prabhasankar P. Influence of natural antioxidants and their carry-through property in biscuit processing. Journal of the Science of Food and Agriculture; 2009; 89(2):288-298. 